Article

\title{
Biodegradable Magnesium Alloy (ZK60) with a Poly(1-lactic)-Acid Polymer Coating for Maxillofacial Surgery
}

\author{
Soo-Hwan Byun ${ }^{1,2,3}$ (), Ho-Kyung Lim ${ }^{2,4}$ (), Sung-Mi Lee ${ }^{5,6}$, Hyoun-Ee Kim ${ }^{5,6}$, \\ Soung-Min Kim ${ }^{2,7}$ (D) and Jong-Ho Lee ${ }^{2,7,8, *(1)}$ \\ 1 Department of Oral \& Maxillofacial Surgery, Dentistry, Sacred Heart Hospital, Hallym University \\ College of Medicine, Anyang 14068, Korea; purheit@daum.net \\ 2 Department of Oral \& Maxillofacial Surgery, School of Dentistry, Seoul National University, \\ Seoul 03080, Korea; ungassi@naver.com (H.-K.L.); smin5@snu.ac.kr (S.-M.K.) \\ 3 Graduate School of Clinical Dentistry, Hallym University, Chuncheon 24252, Korea \\ 4 Department of Oral \& Maxillofacial Surgery, Dentistry, Korea University Guro Hospital, Seoul 08308, Korea \\ 5 Biomedical Implant Convergence Research Center, Advanced Institutes of Convergence Technology, \\ Suwon 16229, Korea; msbb419@snu.ac.kr (S.-M.L.); kimhe@snu.ac.kr (H.-E.K.) \\ 6 Department of Material Science and Engineering, Seoul National University, Seoul 08826, Korea \\ 7 Dental Research Institute, School of Dentistry, Seoul National University, Seoul 03080, Korea \\ 8 Clinical Translational Research Center for Dental Science, Seoul National University Dental Hospital, \\ Seoul 03080, Korea \\ * Correspondence: leejongh@snu.ac.kr; Tel.: +82-2-2072-2630; Fax: +82-2-766-4948
}

Received: 26 March 2020; Accepted: 28 May 2020; Published: 29 May 2020

check for updates

\begin{abstract}
The purpose of this study was to evaluate the mechanical strength and biodegradation of a ZK60 plate coated with poly(l-lactic)-acid polymer (PLLA) in a LeFort I osteotomy canine model for maxillofacial applications. The PLLA-coated ZK60 plate and screw were evaluated using a LeFort I osteotomy canine model based on five beagles. The presence of wound dehiscence, plate exposure, gas formation, inflammation, pus formation, occlusion, food intake, and fistula formation were evaluated. After 12 weeks, these dogs were sacrificed, and an X-ray micro-computed tomography $(\mu \mathrm{CT})$ was conducted. Plate exposure, gas formation, and external fistula were not observed, and the occlusion remained stable. Wound dehiscence did not heal for 12 weeks. CT images did not show plates in all the five dogs. A few screw bodies fixed in the bone remained, and screw heads were completely absorbed after 12 weeks. These findings may be attributed to the inability to optimize the absorption rate with PLLA coating. Rapid biodegradation of the PLLA-coated ZK60 occurred due to the formation of microcracks during the bending process. Further improvement to the plate system with PLLA-coated ZK60 is required using other surface coating methods or alternative Mg alloys.
\end{abstract}

Keywords: biodegradable; plate and screw; magnesium; alloy; ZK60; PLLA coating; maxillofacial

\section{Introduction}

Metal alloying is an innovative approach to improve the mechanical properties of pure metal. Alloying may be advantageous for metals such as magnesium (Mg) used in biomedical applications [1-3]. Most $\mathrm{Mg}$ alloys that have been investigated as biomedical materials are rather complex in alloy composition and contain potentially toxic alloying elements [1]. There is debate regarding the biological effects of alloys containing rare earth metal elements such as yttrium [2,4]. In principle, when selecting biodegradable materials, elements with potential toxic issues should be avoided, or used at the minimal acceptable amounts. In this study, ZK60 was chosen as the biodegradable Mg alloy and its performance as bone-fixation plates in maxillofacial applications was evaluated. 
Zinc (Zn) of ZK60 is a common alloying ingredient in $\mathrm{Mg}$ and has a proper strengthening effect. It helps to overcome the harmful corrosive effect of impurities such as iron and nickel, thus improving the corrosion resistance of the $\mathrm{Mg}$ alloy. Its concentration is usually limited to 3\% for sufficient corrosion resistance [5]. The zirconium $(\mathrm{Zr})$ of $\mathrm{Mg}$ alloys is typically used as a grain refiner, contributing to the strength of the alloy [6]. It also reduces the adverse effects of iron contamination on the corrosion resistance of $\mathrm{Mg}$ alloys [7]. In the $\mathrm{Mg}-\mathrm{Zr}$ binary alloy system, $\mathrm{Zr}$ effectively enhances the corrosion resistance only when its content is less than $0.48 \%$ with no formation of $\mathrm{Zr}$-containing precipitates [8]. The importance of $\mathrm{Zr}$ in the human body is yet to be determined. However, it has been reported that it presents sufficient biocompatibility and osseointegration, both in vitro and in vivo, even outperforming Ti [9].

The degradation behavior of ZK60 was investigated in terms of ion release and $\mathrm{pH}$ of non-static Hank's solution over a period of seven days. Its biocompatibility was evaluated by testing cell viability in vitro under the influence of the eluate of the material. A comparison was made with a WE-type alloy, as well as with hydroxyapatite (HA) to establish the viability of the ZK-type alloy as a potential biodegradable material for biomedical applications. It was found that ZK-type and WE-type alloy samples display biocompatibilities similar to HA after one day of incubation at the tested concentration of the extract [10]. This demonstrates the biocompatibility of ZK60 and WE43, showing that both Mg alloys have better mechanical strength than that of pure Mg. Moreover, the mechanical properties of ZK60 and WE43 could be altered and influenced by various grain sizes, regulation of second particle amounts, and manufacturing methods [6,10].

To overcome the limitation of the mechanical strength of pure $\mathrm{Mg}, \mathrm{ZK} 60$ was selected as it has greater mechanical strength compared to WE43. Generally, clinical applications are possible when the tensile strength of the absorbable plate is greater than $300 \mathrm{MPa}$; the tensile strength of ZK60 is greater than $300 \mathrm{MPa}$. However, like pure Mg, it is anticipated that ZK60 would be rapidly absorbed in body fluids. A previous study demonstrated that ZK60 has an accelerated degradation rate $[10,11]$. Another study demonstrated that $\mathrm{Mg}$ rods had a significantly rapid degradation rate under an applied load in simulated body fluid [12-14].

Based on these outcomes, this study used a biodegradable polymer coating to slow absorption. The coating with biodegradable polymers, including poly(lactide-co-glycolide) (PLGA), poly(l-lactide) acid (PLLA), and poly( $\varepsilon$-caprolactone) (PCL), had proper flexibility. This would endure the tensile strength that could be applied to the inner $\mathrm{Mg}$ [15-17].

Previous studies proved the corrosion resistance and biocompatibility of HA/PLLA-coated $\mathrm{Mg}$ [18-20]. The authors demonstrated mechanically-strained Mg with the HA/PLLA micro-textured coating layer, which preserved its excellent in vitro corrosion resistance and biocompatibility $[18,21]$. However, the HA micro-dots aggravated the delamination of the HA/PLLA coating from the $\mathrm{Mg}$ implant [22]. Based on these studies from the literature and previous findings, PLLA-coated ZK60 is stronger than pure $\mathrm{Mg}$ and therefore was used in this study.

The purpose of this study was to evaluate the mechanical strength and biodegradation of a ZK60 plate coated with PLLA in a LeFort I osteotomy canine model for maxillofacial applications.

\section{Materials and Methods}

\subsection{Design of ZK60 Plate}

ZK60 (Daeryun Co., Shanghai, China) was used to fabricate the plates and screws. Mg alloy plates were made to be slightly thicker and larger than the conventional Ti plates. Plates were an L-shape design with four holes. Mg alloy plates with a thickness of $1.0 \mathrm{~mm}$, and an outer hole size of $5.5 \mathrm{~mm}$, were prepared with a milling machine (Genoss Co., Suwon, Korea) (Figure 1). Plates were soaked in a PLLA-polymer solution (5.0 wt.\% dissolved in dichloromethane) for $5 \mathrm{~min}$ under vacuum pressure at $0.05 \mathrm{MPa}$. To form the PLLA layer, plates were vertically withdrawn from the solution at a rate of $65 \mathrm{~mm} / \mathrm{min}$ using a dip coater [16]. The PLLA-coated plates were rinsed with ethanol and dried in air. The screws were designed to have a self-threading cutting edge to reduce the insertion torque. 
Mg alloy screws $6.0 \mathrm{~mm}$ in length, and $3.4 \mathrm{~mm}$ in diameter, were prepared with a milling machine (Figure 1). Before implantation, all $\mathrm{Mg}$ devices were cleaned by sonication in pure acetone and ethanol for $10 \mathrm{~min}$ each, and sterilized with gamma radiation $\left(2 \times 10^{6} \mathrm{cGy}, 23.5 \mathrm{~Gy} / \mathrm{min}\right)$.
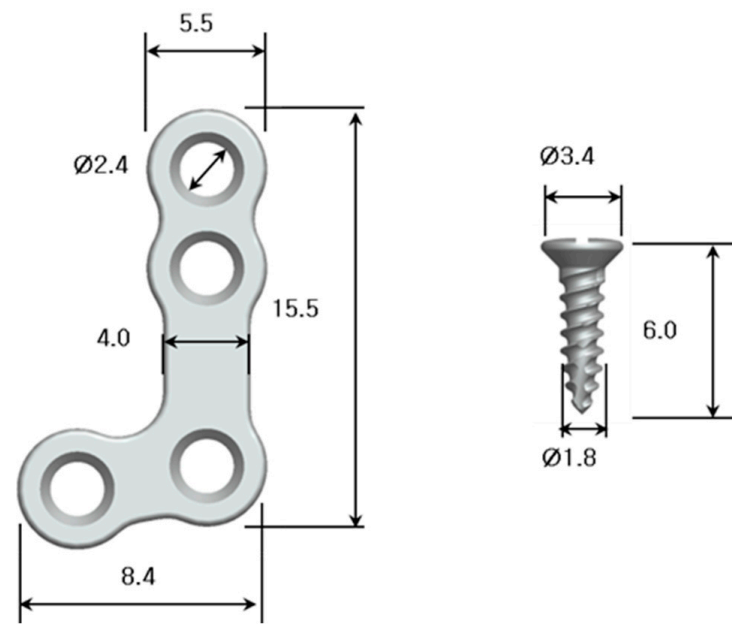

Figure 1. Dimensions and design of the ZK60 plates and screws.

\subsection{Tensile Strength of PLLA-Coated ZK60 Plates}

The tensile strength and elongation of the ZK60 plate was defined as the maximum stress that the plate could withstand while being stretched before breaking [23]. An Instron 8841 (Instron USA, Norwood, MA, USA) was used with a constant speed of $5.0 \mathrm{~mm} / \mathrm{min}$ to measure both tensile strength and elongation of the samples.

\subsection{Bending Strength of PLLA-Coated ZK60 Plates}

The strength of the PLLA coating layer was evaluated to confirm the appearance of microcracks in the plates following the 40 and 60 degree bending. A three-point flexural test was carried out to determine the bending strength. An Instron 8841 (Instron USA, Norwood, MA, USA) was used with a constant bending punch speed of $1.0 \mathrm{~mm} / \mathrm{min}$ and a support distance of $12.0 \mathrm{~mm}$. ASTM F382 (specification and test method for metallic bone plates) was applied as the experimental protocol. The test was stopped during the 40 and 60 degree bending. Delamination of PLLA was confirmed by using a scanning electron microscope (SEM) (FE-SEM, SUPRA 40VP, Carl Zeiss, Oberkochen, Germany).

\subsection{Evaluation of the PLLA-Coated ZK60 Plate Using a LeFort I Osteotomy Canine Model}

This study was approved by the Seoul National University Institutional Animal Care and Use Committee (SNU-160127-6). Five 20 months old beagles (10-15 kg body weight) (Oriental Bio Co., Sungnam, Korea) underwent an initial four weeks adaptation period. General anesthesia was administered intravenously with xylazine $0.1-0.14 \mathrm{~mL} / \mathrm{kg}$ (Rompun ${ }^{\circledR}, 23.32 \mathrm{mg} / \mathrm{mL}$, Bayer Korea Ltd., Seoul, Korea) and tiletamine + zolazepam $0.01 \mathrm{mg} / \mathrm{kg}$ (Zoletil ${ }^{\circledR}, 50 \mathrm{mg} / \mathrm{mL}$, Virbac Corp, Carros, France). Orotracheal intubation was performed using size six tubes without ballooning to secure the airway. Block and infiltration anesthesia was performed intraorally with $2 \%$ lidocaine [24].

A sulcular incision was made from the upper incisor region to the upper second molar region using a \#15 blade. Periosteal elevation was performed posteriorly from the upper second molar to the maxillary tuberosity with minimal damage. A LeFort I osteotomy line was drawn using a pencil; the line was from the top of the piriform aperture to the second molar apex (Figure 2A). Four L-shaped plates were fitted at the anterior buttresses on the canine site and the posterior buttress on the upper site of the third premolar [25]. When fitting the plates, screws were positioned to avoid the osteotomy line. After the plates were fitted, 16 holes were made on the bone with a $1.5 \mathrm{~mm}$ sized drill at a speed of 
$1500 \mathrm{rpm}$ (Dentium, Suwon, Korea), with sufficient saline irrigation. Plates were fixed using 16 screws. The four plates and 16 screws were then removed. The LeFort I osteotomy was performed carefully on the maxillary tuberosity area using a reciprocating saw to ensure that the periosteum was not damaged (Figure 2B). The operator confirmed a complete anteroposterior fracture. The separated maxillary bone was repositioned after hemostasis, and the four plates and 16 screws were fixed to the preformed holes (Figure 2C). Copious irrigation and interrupted sutures were performed using 4-0 nylon sutures (Dafilon ${ }^{\circledR}$, Braun, Germany). Pulverized feed was provided for four weeks following the operation, in the same amounts prior to surgery. Analgesics $(0.2 \mathrm{mg} / \mathrm{kg}$, Meloxicam, Hanall, Korea) and antibiotics (30-60 mg/kg, Cephalexin cap, Ildong, Korea) were mixed with the pulverized feed and provided for up to $7 \mathrm{~d}$ following surgery. A regular diet was provided after four weeks.

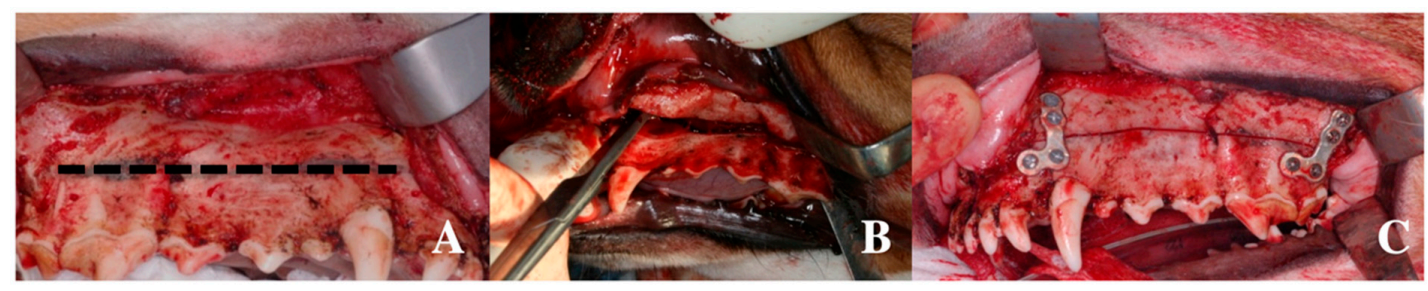

Figure 2. Intraoperative clinical photograph of the LeFort I osteotomy canine model. (A) LeFort I osteotomy line was planned; (B) LeFort I osteotomy was performed from the top of the piriform aperture to the second molar apex; (C) fixation of the four plates and 16 screws on each dog.

\subsection{Clinical Evaluation}

The presence of wound dehiscence, plate exposure, gas formation, inflammation, pus formation, occlusion, food intake, and fistula formation were evaluated weekly. Occlusion was evaluated by using shim stock and photographs taken before and after the experiment. An examiner evaluated the mobility and stability of the maxilla by holding the cranial bone with the left hand and the anterior portion of the maxilla with the right hand, and shaking back and forth. The presence of wound dehiscence, plate exposure, gas formation, inflammation, pus formation, and fistula formation were also checked weekly by intraoral/extraoral examination of both maxillary areas without general anesthesia. The intraoral area was recorded by taking clinical photographs. The symptoms were evaluated by comparing the photographs thoroughly.

\subsection{Evaluation of Absorption Rate Using $\mu C T$}

Five dogs were sacrificed after 12 weeks, and X-ray micro-computed tomography $(\mu \mathrm{CT})$ (SkyScan1173; SkyScan, Kontich, Belgium) was taken. Gas formation and the absorption rate of the plates and screws were evaluated with $\mu \mathrm{CT}$ images.

\section{Results}

\subsection{Chemical Composition of ZK60}

The ZK60 used in this study was composed of magnesium, zinc, zirconium, and other elements and impurities (Table 1).

Table 1. Chemical composition of ZK60.

\begin{tabular}{cccccccccc}
\hline ASTM No. & $\begin{array}{c}\text { Mg } \\
(\mathbf{m i n})\end{array}$ & Zn & Zr & Mn & Fe & Si & Al & Cu & $\begin{array}{c}\text { Other } \\
\text { Impurities }\end{array}$ \\
\hline ZK60 & Bal. & $4.8-6.2$ & 0.64 & 0.012 & 0.0021 & 0.0016 & 0.0014 & 0.001 & 0.3 \\
\hline
\end{tabular}




\subsection{Tensile Strength of ZK60 Plates}

The tensile strength and elongation of PLLA-coated ZK60 plates are described in Table 2. During the tensile tests, initial necking of ZK60 was found at the yield point, and the cross-sectional area of the samples decreased continuously until fracture occurred.

Table 2. Improved mechanical properties of ZK60.

\begin{tabular}{cccc}
\hline ZK60 & $\begin{array}{c}\text { Ultimate Tensile } \\
\text { Strength }(\mathbf{M P a})\end{array}$ & $\begin{array}{c}\text { Tensile Yield } \\
\text { Strength }(\mathbf{M P a})\end{array}$ & Elongation (\%) \\
\hline $\begin{array}{c}\text { Average } \\
\pm \text { S.D. }\end{array}$ & $327.94 \pm 20.10$ & $251.16 \pm 33.43$ & $15.12 \pm 1.95$ \\
\hline
\end{tabular}

S.D.: standard deviation.

\subsection{Bending Strength of PLLA-Coated ZK60 Plates}

Approximately $50 \%$ of the plates exhibited microcracks following a 40 degree bending; while $100 \%$ of the plates had microcracks at 60 degree bending. Necking of the samples was not observed during bending deformation. It is likely that the local microcracks were formed on the topmost (higher tensile strain) part of the coating layer in the plates during bending, and some of these small cracks propagated leading to larger cracks. The cracks grew along the interface between the coating layer and the $\mathrm{Mg}$ substrate. Finally, some of these cracks combined into a single crack, which formed in the direction perpendicular to the coating layer.

\subsection{Evaluation of PLLA-Coated ZK60 Plate Using a LeFort I Osteotomy Canine Model}

\subsubsection{Clinical Evaluation}

None of the dogs encountered any specific problems during the surgical procedure. However, the wound dehiscence that occurred at the time point between two and three weeks did not heal during the observation period (Figure 3A). The inflammatory symptoms with extraoral fistula continued from two weeks to twelve weeks (Figure 3B-D). Plaque accumulation was observed at the cervical area of maxillary teeth after 12 weeks (Figure 3B). Wound dehiscence was covered with plaque and calculus. Plate exposure and gas formation were not observed, and occlusion remained stable (Figure 3E). Instability of the maxilla was not observed, and there was no difference in food intake during the observation period.

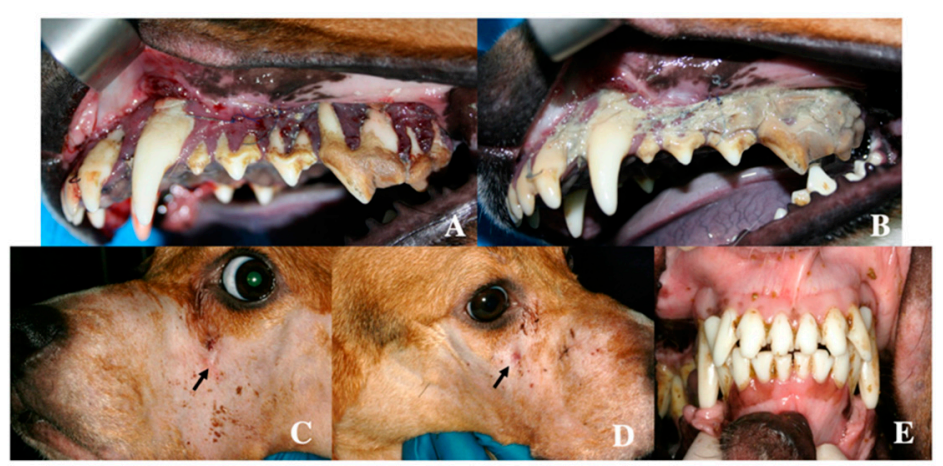

Figure 3. Postoperative clinical photographs after two weeks and 12 weeks. (A) wound dehiscence after two weeks; (B) inflammatory symptoms after 12 weeks; (C) and (D) fistula formation at infraorbital area (arrow: fistula); (E) stable occlusion after 12 weeks.

\subsubsection{Evaluation of Absorption Rate Using $\mu \mathrm{CT}$}

Gas formation was observed on the CT images acquired at 12 weeks, and no remaining plates were observed in the five dogs. During evaluation of the absorption based on the $\mu \mathrm{CT}$ images, all plates 
were found to have deviated from their original position as they were absorbed, so it was difficult to overlay the plates. Twelve screw bodies fixed in the bone remained, but the screw heads had mostly been absorbed after 12 weeks (Figure 4).

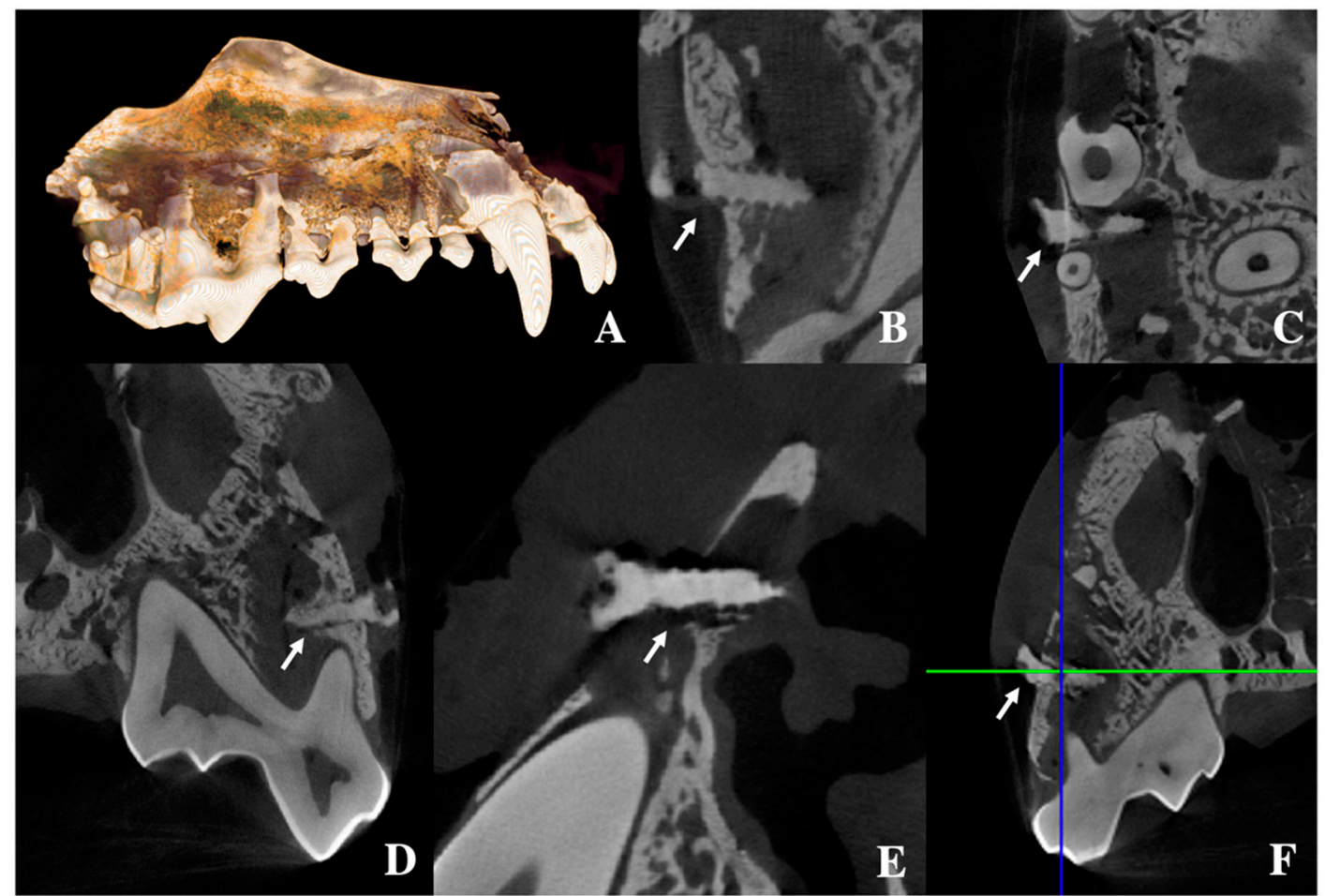

Figure 4. Radiological evaluation after 12 weeks. Only a few screw bodies fixed in the bone remained, and screw heads had mostly been absorbed after 12 weeks (arrow: remaining screw). (A) harvested maxilla; (B) separated screw head; (C) completely absorbed screw head; (D-F) partially absorbed screw heads.

\section{Discussion}

In recent studies, the PLLA coating layer of the Mg alloy showed proper corrosion resistance, where a very low rate of hydrogen gas formation was observed, which was compatible with the protective HA coating layer [22,26]. The PLLA coating layer of the Mg alloy presented excellent in-vitro biocompatibility, and a large number of MC3T3-E1 cells were attached to the coating layer and had spread sufficiently [22]. The PLLA coating layer of the Mg alloy could be maintained without significant cracks even after $5 \%$ elongation [22]. As mentioned before, these findings prompted this study's use of PLLA-coated ZK60 as the biodegradable material for maxillofacial application.

However, the PLLA-coated ZK60 plate was absorbed in just 12 weeks, causing an inflammatory response due to rapid absorption in all dogs. The rapid absorption generated gas and induced the wound dehiscence in early stages. Although ZK60 has better mechanical properties than WE43, it is known that it has a more rapid absorption rate when it comes into contact with body fluids. In a previous study, ZK60 had significantly degraded in nine weeks and was completely degraded after 12 weeks [10].

The PLLA was slightly elastic, however, the PLLA coating could not endure the bending force while fitting on the bone. When fitting the plates, a microcrack would occur due to the bending force. Body fluids would invade the ZK60 through the microcrack of the plate, potentially making the PLLA coating redundant. This study revealed that microcracks appeared in the PLLA-coated ZK60 plate during the bending test and the animal experiment. Fixation plates are usually bended for specific adaption to the bone in maxillofacial surgery. The bending is performed in the range between 0 and 90 degrees; the bending test conducted in this study showed a $50 \%$ probability of microcrack formation 
under 40 degree bending and $100 \%$ probability of microcrack formation under 60 degrees bending. Based on these results, the PLLA-coated ZK60 plate should not be used in clinical applications for fixation surgery. The dynamic bending load promotes the degradation of $\mathrm{Mg}$ and then accelerates the loss of the plates' mechanical properties. The coating layer was severely cracked due to its brittleness with little plastic deformation ability. The PLLA coating layer was often found torn and detached from the $\mathrm{Mg}$ substrate because of the relatively weak interfacial bonding [13,14,22].

Interfacial delamination also occurred due to the weak bonding between the PLLA coating layer and the ZK60; this would not prevent the aggressive degradation of the ZK60 [27]. Consideration must be given to alternative methods to achieve a safe coating on the ZK60 plates. A strong bonding between the PLLA coating layer and the ZK60 may be achieved by blasting the surface of the ZK60. Moreover, if the plate was adjusted prior to the PLLA coating, there may be a reduction in the likelihood of microcracks occurring. The thickness of the PLLA coating may also be adjusted by controlling the dipping time in the PLLA-polymer solution.

In previous studies, the general long-term absorption behavior of WE-type and ZK-type alloys was evaluated by the static immersion test in which the concentration of chloride ions was maintained at a constant level [10]. Such a static immersion system is unable to precisely simulate the actual physiological conditions in the human body because the body fluid circulates dynamically, and ion concentrations differ in various parts of the human body [28]. Nevertheless, the local concentration of chloride ions is one of the most important factors that determine the absorption rate of $\mathrm{Mg}$ alloys when they are exposed to an aggressive electrolyte, such as simulated body fluid or a sodium chloride solution. Studies have demonstrated varying behavior based on the absorption rate [28].

The absorption rate of $\mathrm{Mg}$ alloys must not exceed the healing rate of the bone. Thus, the $\mathrm{Mg}$ alloy should remain in the body and maintain its mechanical integrity for at least 12-18 weeks while the bone tissue heals [2]. The results from this study suggest that the absorption rate of the ZK60 plate was too rapid, despite the PLLA coating. Therefore, further optimization of Mg alloy plates, using innovative coating methods or other alloy compositions, is needed to achieve an appropriate rate of absorption [29-36]. These further studies should be conducted with extensive in-vitro tests before in-vivo tests.

\section{Conclusions}

ZK60 had proper mechanical strength for maxillofacial surgery; however, it showed rapid absorption. Various coating methods were investigated to slow the absorption rate during the biodegradation of Mg alloys. The PLLA coating layer showed an excellent stability under tensile force, which is a crucial property for clinical application. However, the PLLA coating layer was damaged due to the brittleness of the polymer following the application of a bending force.

This study demonstrated that the absorption rate of ZK60 could not be enhanced with PLLA coating for maxillofacial applications. Rapid biodegradation of the PLLA-coated ZK60 was thought to be due to the formation of microcracks by the bending process. Plates are usually bended during fixation surgery for precise adaptation, so PLLA-coating would not prevent the aggressive degradation of the ZK60. To overcome these limitations, plate systems made with PLLA-coated ZK60 need further improvement with other surface coating materials/methods or alternative Mg alloys.

Author Contributions: Conceptualization, S.-H.B., H.-E.K., S.-M.K., and J.-H.L.; funding acquisition, J.-H.L.; investigation, S.-M.L.; methodology, S.-H.B., H.-K.L., S.-M.L., and H.-E.K.; resources, S.-M.L.; supervision, S.-M.K. and J.-H.L.; validation, S.-M.K.; writing-original draft, S.-H.B.; writing—review and editing, S.-H.B., H.-K.L., and J.-H.L. All authors have read and agreed to the published version of the manuscript.

Funding: This research was supported by a grant from the Korea Health Technology R\&D Project through the Korea Health Industry Development Institute (KHIDI), the Ministry of Health and Welfare, Republic of Korea (grant HI15C1535). This work was supported by the Technology development Program (S2357070) funded by the Ministry of SMEs and Startups (MSS, Korea). This research was supported by the National Research Foundation of Korea (NRF) grant funded by the Korea government (MSIT) (No. 2017R1C1B5076558). 
Acknowledgments: We would like to thank Dentium Co. and Genoss Co.

Conflicts of Interest: The authors declare no potential conflicts of interest with respect to the authorship and/or publication of this article.

\section{References}

1. Witte, F.; Fischer, J.; Nellesen, J.; Crostack, H.A.; Kaese, V.; Pisch, A.; Beckmann, F.; Windhagen, H. In vitro and in vivo corrosion measurements of magnesium alloys. Biomaterials 2006, 27, 1013-1018. [CrossRef] [PubMed]

2. Witte, F.; Kaese, V.; Haferkamp, H.; Switzer, E.; Meyer-Lindenberg, A.; Wirth, C.J.; Windhagen, H. In vivo corrosion of four magnesium alloys and the associated bone response. Biomaterials 2005, 26, 3557-3563. [CrossRef] [PubMed]

3. Liu, C.; Ren, Z.; Xu, Y.; Pang, S.; Zhao, X.; Zhao, Y. Biodegradable Magnesium Alloys Developed as Bone Repair Materials: A Review. Scanning 2018, 2018, 9216314. [CrossRef] [PubMed]

4. Gu, X.; Zheng, Y.; Cheng, Y.; Zhong, S.; Xi, T. In vitro corrosion and biocompatibility of binary magnesium alloys. Biomaterials 2009, 30, 484-498. [CrossRef]

5. Lin, X.; Tan, L.; Zhang, Q.; Yang, K.; Hu, Z.; Qiu, J.; Cai, Y. The in vitro degradation process and biocompatibility of a ZK60 magnesium alloy with a forsterite-containing micro-arc oxidation coating. Acta Biomater. 2013, 9, 8631-8642. [CrossRef] [PubMed]

6. Song, Y.; Wang, M.; Zong, Y.; He, R.; Jin, J. Grain Refinement by Second Phase Particles under Applied Stress in ZK60 Mg Alloy with Y through Phase Field Simulation. Materials 2018, 11, 1903. [CrossRef]

7. Wang, B.; Huang, P.; Ou, C.; Li, K.; Yan, B.; Lu, W. In vitro corrosion and cytocompatibility of ZK60 magnesium alloy coated with hydroxyapatite by a simple chemical conversion process for orthopedic applications. Int. J. Mol. Sci. 2013, 14, 23614-23628. [CrossRef]

8. Saldana, L.; Mendez-Vilas, A.; Jiang, L.; Multigner, M.; Gonzalez-Carrasco, J.L.; Perez-Prado, M.T.; Gonzalez-Martin, M.L.; Munuera, L.; Vilaboa, N. In vitro biocompatibility of an ultrafine grained zirconium. Biomaterials 2007, 28, 4343-4354. [CrossRef]

9. Kulakov, O.B.; Doktorov, A.A.; D'Iakova, S.V.; Denisov-Nikol'skii Iu, I.; Grotz, K.A. Experimental study of osseointegration of zirconium and titanium dental implants. Morfologiia 2005, 127, 52-55.

10. Huan, Z.G.; Leeflang, M.A.; Zhou, J.; Fratila-Apachitei, L.E.; Duszczyk, J. In vitro degradation behavior and cytocompatibility of Mg-Zn-Zr alloys. J. Mater. Sci. Mater. Med. 2010, 21, 2623-2635. [CrossRef]

11. Zhang, S.; Bi, Y.; Li, J.; Wang, Z.; Yan, J.; Song, J.; Sheng, H.; Guo, H.; Li, Y. Biodegradation behavior of magnesium and ZK60 alloy in artificial urine and rat models. Bioact. Mater. 2017, 2, 53-62. [CrossRef] [PubMed]

12. Tian, Q.; Antonio Mendez, J.; Rivera-Castaneda, L.; Mahmood, O.; Showalter, A.; Ang, E.; Kazmi, S.; Liu, H. Development of a Novel Loading Device for Studying Magnesium Degradation under Compressive Load for Implant Applications. Mater. Lett. 2018, 217, 27-32. [CrossRef] [PubMed]

13. Saad, A.P.M.; Syahrom, A. Study of dynamic degradation behaviour of porous magnesium under physiological environment of human cancellous bone. Corros. Sci. 2018, 131, 45-56. [CrossRef]

14. Li, X.; Wang, Y.; Chu, C.; Han, L.; Bai, J.; Xue, F. A study on Mg wires/poly-lactic acid composite degradation under dynamic compression and bending load for implant applications. J. Mech. Behav. Biomed. Mater. 2020, 105, 103707. [CrossRef]

15. Wong, H.M.; Yeung, K.W.; Lam, K.O.; Tam, V.; Chu, P.K.; Luk, K.D.; Cheung, K.M. A biodegradable polymer-based coating to control the performance of magnesium alloy orthopaedic implants. Biomaterials 2010, 31, 2084-2096. [CrossRef]

16. Diez, M.; Kang, M.H.; Kim, S.M.; Kim, H.E.; Song, J. Hydroxyapatite (HA)/poly-L-lactic acid (PLLA) dual coating on magnesium alloy under deformation for biomedical applications. J. Mater. Sci. Mater. Med. 2016, 27, 34. [CrossRef]

17. Wang, J.; Tang, J.; Zhang, P.; Li, Y.; Wang, J.; Lai, Y.; Qin, L. Surface modification of magnesium alloys developed for bioabsorbable orthopedic implants: A general review. J. Biomed. Mater. Res. B Appl. Biomater. 2012, 100, 1691-1701. [CrossRef]

18. Qi, Z.R.; Zhang, Q.; Tan, L.L.; Lin, X.; Yin, Y.; Wang, X.L.; Yang, K.; Wang, Y. Comparison of degradation behavior and the associated bone response of ZK60 and PLLA in vivo. J. Biomed. Mater. Res. A 2014, 102, 1255-1263. [CrossRef] 
19. Li, B.; Thomas, W. The Challenges of Magnesium, Corrosion rate with and without PLLA. In Orthopedic Biomaterials: Advances and Applications; Springer: Berlin, Germany, 2018.

20. Wang, Y.; Li, X.; Chen, M.; Zhao, Y.; You, C.; Li, Y.; Chen, G. In Vitro and in Vivo Degradation Behavior and Biocompatibility Evaluation of Microarc Oxidation-Fluoridated Hydroxyapatite-Coated Mg-Zn-Zr-Sr Alloy for Bone Application. ACS Biomater. Sci. 2019, 5, 2858-2876. [CrossRef]

21. Zhao, D.; Witte, F.; Lu, F.; Wang, J.; Li, J.; Qin, L. Current status on clinical applications of magnesium-based orthopaedic implants: A review from clinical translational perspective. Biomaterials 2017, 112, 287-302. [CrossRef]

22. Kim, S.M.; Kang, M.H.; Kim, H.E.; Lim, H.K.; Byun, S.H.; Lee, J.H.; Lee, S.M. Innovative micro-textured hydroxyapatite and poly(l-lactic)-acid polymer composite film as a flexible, corrosion resistant, biocompatible, and bioactive coating for Mg implants. Mater. Sci. Eng. C Mater. Biol. Appl. 2017, 81, 97-103. [CrossRef] [PubMed]

23. Buijs, G.J.; van der Houwen, E.B.; Stegenga, B.; Bos, R.R.; Verkerke, G.J. Mechanical strength and stiffness of biodegradable and titanium osteofixation systems. J. Oral. Maxillofac. Surg. 2007, 65, 2148-2158. [CrossRef] [PubMed]

24. Viscasillas, J.; Seymour, C.J.; Brodbelt, D.C. A cadaver study comparing two approaches for performing maxillary nerve block in dogs. Vet. Anaesth. Analg. 2013, 40, 212-219. [CrossRef] [PubMed]

25. Zhao, L.; Xu, Z.; Yang, Z.; Wang, J.; Wei, X.; Tang, T.; Zhao, Z. Quantitative research using computed tomographic scanning of beagle jaws for determination of safe zones for micro-screw implantation. Ann. Anat. Anat. Anz. 2009, 191, 379-388. [CrossRef] [PubMed]

26. Lorenz, C.; Brunner, J.G.; Kollmannsberger, P.; Jaafar, L.; Fabry, B.; Virtanen, S. Effect of surface pre-treatments on biocompatibility of magnesium. Acta Biomater. 2009, 5, 2783-2789. [CrossRef]

27. Xu, L.; Yamamoto, A. Characteristics and cytocompatibility of biodegradable polymer film on magnesium by spin coating. Colloids Surf. B Biointerfaces 2012, 93, 67-74. [CrossRef]

28. Levesque, J.; Hermawan, H.; Dube, D.; Mantovani, D. Design of a pseudo-physiological test bench specific to the development of biodegradable metallic biomaterials. Acta Biomater. 2008, 4, 284-295. [CrossRef]

29. Gray-Munro, J.E.; Seguin, C.; Strong, M. Influence of surface modification on the in vitro corrosion rate of magnesium alloy AZ31. J. Biomed. Mater. Res. A 2009, 91, 221-230. [CrossRef]

30. Razavi, M.; Fathi, M.; Savabi, O.; Tayebi, L.; Vashaee, D. Biodegradable Magnesium Bone Implants Coated with a Novel Bioceramic Nanocomposite. Materials 2020, 13, 1315. [CrossRef]

31. Zhang, Z.Q.; Wang, L.; Zeng, M.Q.; Zeng, R.C.; Kannan, M.B.; Lin, C.G.; Zheng, Y.F. Biodegradation behavior of micro-arc oxidation coating on magnesium alloy-from a protein perspective. Bioact. Mater. 2020, 5, 398-409. [CrossRef]

32. Liu, D.; Li, Y.; Zhou, Y.; Ding, Y. The Preparation, Characterization and Formation Mechanism of a Calcium Phosphate Conversion Coating on Magnesium Alloy AZ91D. Materials 2018, 11, 908. [CrossRef] [PubMed]

33. Liu, W.; Li, T.; Yang, C.; Wang, D.; He, G.; Cheng, M.; Wang, Q.; Zhang, X. Lithium-Incorporated Nanoporous Coating Formed by Micro Arc Oxidation (MAO) on Magnesium Alloy with Improved Corrosion Resistance, Angiogenesis and Osseointegration. J. Biomed. Nanotechnol. 2019, 15, 1172-1184. [CrossRef] [PubMed]

34. Cui, L.Y.; Wei, G.B.; Zeng, R.C.; Li, S.Q.; Zou, Y.H.; Han, E.H. Corrosion resistance of a novel SnO2-doped dicalcium phosphate coating on AZ31 magnesium alloy. Bioact. Mater. 2018, 3, 245-249. [CrossRef] [PubMed]

35. Xiong, Y.; Hu, Q.; Song, R.; Hu, X. LSP/MAO composite bio-coating on AZ80 magnesium alloy for biomedical application. Mater. Sci. Eng. C Mater. Biol. Appl. 2017, 75, 1299-1304. [CrossRef] [PubMed]

36. Ren, Y.; Babaie, E.; Lin, B.; Bhaduri, S.B. Microwave-assisted magnesium phosphate coating on the AZ31 magnesium alloy. Biomed. Mater. 2017, 12, 045026. [CrossRef] [PubMed]

(C) 2020 by the authors. Licensee MDPI, Basel, Switzerland. This article is an open access article distributed under the terms and conditions of the Creative Commons Attribution (CC BY) license (http://creativecommons.org/licenses/by/4.0/). 